University of Wollongong

Research Online

Faculty of Informatics - Papers (Archive)

Faculty of Engineering and Information

Sciences

9-7-2007

\title{
Minimizing Product Shrinkage across the Supply Chain using Radio Frequency Identification: a Case Study on a Major Australian Retailer
}

\author{
N. Huber \\ University of Wollongong, nickhuber@yahoo.com \\ Katina Michael \\ University of Wollongong, katina@uow.edu.au
}

Follow this and additional works at: https://ro.uow.edu.au/infopapers

Part of the Physical Sciences and Mathematics Commons

\section{Recommended Citation}

Huber, N. and Michael, Katina: Minimizing Product Shrinkage across the Supply Chain using Radio Frequency Identification: a Case Study on a Major Australian Retailer 2007.

https://ro.uow.edu.au/infopapers/556 


\title{
Minimizing Product Shrinkage across the Supply Chain using Radio Frequency Identification: a Case Study on a Major Australian Retailer
}

\begin{abstract}
This paper identifies the contributing factors of product shrinkage and investigates the current state of anti-theft technology as part of the loss prevention strategy for a major Australian retailer. Using a case study approach a total of eleven interviews were conducted with employees of the retailer to identify factors contributing to product shrinkage and ways to overcome these through the use of radio frequency identification (RFID) technology. Known sources of product shrinkage included: warehouse discrepancies, internal and external theft, product recalls, shop return fraud, extortion, human and system error, poor stock control, poor rotation of stock, misplaced product items, lost products, product spoilage and damage. Each of the retailer's stores, in the chain of approximately 700, loses about 350000 Australian dollars to product shrinkage every six months. This paper argues that RFID would act as a partial solution toward the minimization of the retailer's product shrinkage and provide greater visibility throughout the supply chain.
\end{abstract}

\section{Keywords}

product shrinkage, supply chain management, electronic article surveillance, RFID, bar code, loss prevention, interviews

\section{Disciplines}

Physical Sciences and Mathematics

\section{Publication Details}

This paper was originally published as Huber, $\mathrm{N}$ and Michael, $\mathrm{K}$, Minimizing Product Shrinkage across the Supply Chain using Radio Frequency Identification: a Case Study on a Major Australian Retailer, The Sixth International Conference on Mobile Business, 9-11 July 2007, Toronto, Canada, 1-8. 


\title{
Minimizing Product Shrinkage across the Supply Chain using Radio Frequency Identification: a Case Study on a Major Australian Retailer
}

\author{
Nicholas Huber, Katina Michael \\ School of Information Systems and Technology, University of Wollongong \\ \{nph229, katina\}@uow.edu.au
}

\begin{abstract}
This paper identifies the contributing factors of product shrinkage and investigates the current state of anti-theft technology as part of the loss prevention strategy for a major Australian retailer. Using a case study approach a total of eleven interviews were conducted with employees of the retailer to identify factors contributing to product shrinkage and ways to overcome these through the use of radio frequency identification (RFID) technology. Known sources of product shrinkage included: warehouse discrepancies, internal and external theft, product recalls, shop return fraud, extortion, human and system error, poor stock control, poor rotation of stock, misplaced product items, lost products, product spoilage and damage. Each of the retailer's stores, in the chain of approximately 700, loses about 350000 Australian dollars to product shrinkage every six months. This paper argues that RFID would act as a partial solution toward the minimization of the retailer's product shrinkage and provide greater visibility throughout the supply chain.
\end{abstract}

\section{Introduction}

This paper will determine the contributing factors of product shrinkage and investigate the current state of electronic identification as part of a loss prevention strategy in a case study of an Australian retailer. The main method of data collection for the case study was using interviews. In total, eleven interviews were conducted with members of the retailer's Loss Prevention Department, and managers of departments within retail outlets in two regions of New South Wales in Australia. The retailer is currently using barcode systems to identify products, and electronic article surveillance (EAS) as an anti-theft technology. As a key driver to the existence of a loss prevention strategy, product shrinkage and sources which comprise it were identified. Radio frequency identification (RFID) is then proposed as a partial solution to minimize the retailer's product shrinkage. This paper aims to explore how RFID could replace EAS given its superior functionality.

\section{Background of the retailer}

The grocery retailer chosen for the case is one of Australia's leading supermarket chains, with approximately 270 stores in New South Wales and over 700 Australia wide. Supported by thousands of suppliers, the retailer has over 42,000 product lines on sale to consumers. Product lines include both Australian made consumer goods and internationally imported goods. Goods on sale by the retailer consist of long-life foods (e.g. confectionary, canned fruit, condiments), perishable foods (e.g. vegetables, bread, frozen meals) and general merchandise (e.g. electrical appliances, cosmetics, liquor). Over 100,000 staff members across Australia work together to get products into stores and on displays, which are then purchased by over 13 million customers each week.

\section{Methodology}

The research was conducted using eleven semistructured interviews with employees from Loss Prevention, and various departments within five retail stores. All the interviews were conducted in August and September of 2006. The interviewees had the following job descriptions: Loss Prevention Manager (1), Loss Prevention Investigator, Loss Prevention Manager (2), Liquor Manager, Grocery Manager, Store Services Manager, Store Trading Manager, Store Manager, Delicatessen Manager, Night-fill Captain, and Customer Implementation Executive. Employees within Loss Prevention work as a team to ensure policies and procedures are adhered to at a store level (figure 1). Product shrinkage is considered to be the general indicator of how well a store's loss prevention strategy is performing, or how well it has been executed. Furthermore, the primary motivator of loss prevention is to reduce product shrinkage. As stated by the Loss Prevention Manager (2): "[The Retail 
Organization] has been fairly focused on shrinkage for the last 5 years." The interviews were transcribed and then analyzed using the Leximancer computer assisted qualitative data analysis software (CAQDAS). As a tool used to extract main concepts from documents, the researcher was able to use these concepts in the creation of themes to be addressed in the narrative.

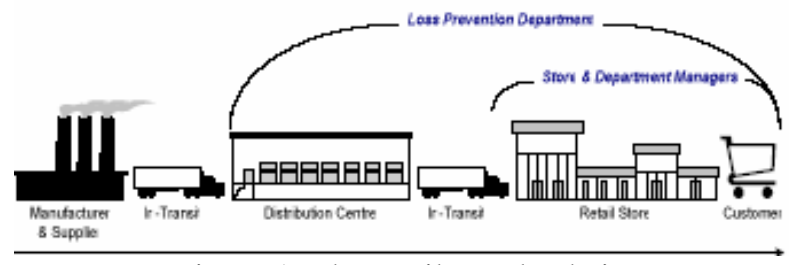

Figure 1. The retail supply chain

\section{The retailer's legacy systems}

The retailer currently uses barcodes for the automatic identification of products across the supply chain, and EAS for anti-theft purposes as part of a loss prevention strategy. Both systems have distinct functions and operate independently of one another. Barcodes provide a way to record damaged products and identify targeted areas, whereas EAS is used to deter thieves.

\subsection{Barcode for product identification}

The retailer's barcode system is primarily used to identify products in a variety of daily activities. One of these activities, closely related to loss prevention, is its ability to help keep track of damaged goods. For instance, damaged products can be scanned and automatically declared as 'damaged goods', electronically recorded and then disposed of. This process notifies the automatic stock ordering system that products are damaged and need to be re-ordered, thus helping to maintain product availability in the retail outlet. Barcodes can assist in minimizing product shrinkage by recording damaged products but exist primarily to semi-automate supply chain operations. When the Night-fill Captain of one of the retailer's leading stores was asked if barcodes play a role in minimizing product shrinkage, he responded: "[i]t makes you aware of it. It doesn't actually deter or prevent it in any way. It gives you more knowledge of what's going on and where the targeted areas might be." In other words, stock which has been misplaced or stolen is not readily identified by retail staff. As supported by the Loss Prevention Investigator: "[b]arcoding really has no impact. All it does is identify that we have lost something by scanning it at the end of the day." Furthermore, these targeted areas are usually brought to the retailer's attention once a store has been targeted by a thief or when stock fails to arrive from the distribution centre. It is in this light that barcodes offer knowledge through recording goods as damaged or by identifying targeted areas. As a result, barcodes play a minor role in a loss prevention strategy. EAS however, plays a more active role in loss prevention as an effective deterrent against theft.

\subsection{Electronic article surveillance as a theft deterrent at the retail outlet}

The retail organization currently utilizes EAS as part of its loss prevention strategy. The system's primary activity is to reduce theft within supermarkets and liquor stores. According to Lahiri (2006), EAS tags are generally unaffected by magnets and are available in various sizes to be applied [1]. The retailer uses a combination of adhesive and reusable EAS tags which are strategically fitted to certain products.

EAS antennas, also known as gateways, are installed at store entrances and exits (Figure 2). When a product with an active tag passes through a gateway, an alarm sounds to notify staff of possible theft. For the retailer's particular application, EAS tags are attached to products at the item-level. Tagged products generally include high theft lines and high dollar value items. Not all products were found to be tagged, in fact, most products were not secured by the EAS system. As expressed by the Loss Prevention Manager (1):

it's what we deem to be high-theft lines and obviously what our stores are recording as known stolen as well. So you look at the high-theft lines as well as the most attractive lines, some of it is going to be cost driven just by the unit price, in terms of what we put an EAS tag on. The retailer is currently testing new reusable EAS tags designed to be attached to liquor bottles.
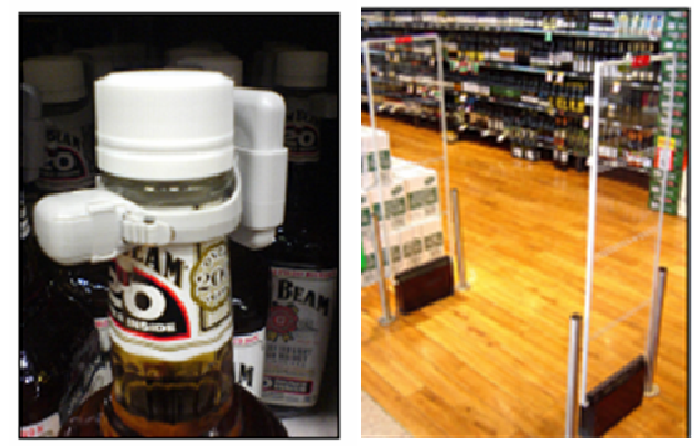

Figure 2. EAS tag and EAS gates in a liquor store

Instead of using an adhesive tag, which is easily removed or a tag which is concealed within a packet, reusable tags are encased in high density plastic and manually fitted to products. Attached to the neck of a bottle with a zip locking mechanism, this new type of 
tag is removed by staff with a decoupling device at point of sale. As revealed by the Loss Prevention Manager (2): "[w]e are running trials at the moment on new tags in our liquor departments in five stores. They have been extremely successful, as they have minimized product shrinkage across our range of spirits by $62 \%$, which is a great result." Other than the obvious benefit of the tag's ability to be reused, this type of EAS tag has a number of other benefits. The tags are difficult to remove by hand, tagged products 'standout' and regularly deter thieves. "Many times I have seen people walk into a store and be overwhelmed by the EAS tagging" explained the Sydney-based liquor manager. The use of reusable tags by the retailer may help to minimize product shrinkage by deterring thieves, however, additional labor is required by retail employees to manually apply and remove tags.

Products bearing adhesive or concealed tags within a product's packaging are either tagged in-store manually by retail employees or source-tagged from the supplier. As revealed by the Store Trading Manager: "...we have a specific list that we have got to stick to. A lot of the stock actually comes in pre-tagged now." Source-tagged products provide the only example where EAS is used across the supply chain. However, by the same token, those tags remain idle until they come in contact with an EAS antenna or tag deactivator. As suggested by the Loss Prevention Manager (1), with the help of a recently designated Source Tag Manager the retailer is attempting to extend the 'source-tagged list' and push suppliers to tag products at the point of manufacture. Essentially, suppliers then take part in the overall process of applying EAS tags to products which will definitely reduce some overhead costs for the retailer. However despite this, it was found that the retailer's EAS system had a number of inefficiencies.

The retailer's thoughts on the overall performance of the system varied. One of the main questions relating to EAS was whether the technology was considered a deterrent or a total solution. All employees agreed that it was definitely a deterrent and it would be hard to find a total solution. As supported by the Loss Prevention Investigator: "[1]ook as a deterrent, yes. As I said before it's not the be-all and end-all. There's certainly some new stuff coming out." As part of a loss prevention strategy, EAS was believed to be a deterrent on many occasions. When the Loss Prevention Manager (1) was asked for his opinion, he also said that it was a deterrent: "I wouldn't say it's a total solution. I suppose with any loss prevention initiative or procedure, there are thousands of bricks in the wall and EAS is one of those." To further support the responses of the loss prevention staff, Lahiri also suggests that RFID is an "effective deterrent against theft" [2]. To be an effective anti-theft solution within a retail environment an EAS system is required to operate consistently and meet the demands of customer traffic. During initial testing phases of EAS systems some time ago, tests were conducted between two major brands. The Loss Prevention Manager (2) was asked whether he was happy with the overall performance of the EAS system: "Not really... I thought ' $\mathrm{X}$ ' performed better than ' $\mathrm{Y}$ '. But unfortunately we have invested in the 'Y' system." This suggests that a retailer may not always consider an EAS system's level of performance a high priority. Other factors, such as the cost of a system may also have a direct effect on the retailer's willingness to invest in an anti-theft solution.

In one particular case, the way in which the system was installed revealed some drawbacks of the technology. When the Liquor Manager from one of the retailer's leading liquor stores was asked if he was happy with the overall performance of the system, he revealed "our gates leading out of our shop into the centre are too far apart, so there is a gap in the middle that can be exploited if you walk down the middle." He believed that incorrect measurements had been made during the installation of the EAS system and as a result, he was unhappy with the overall performance of the system. An additional view which also supports a negative outlook on EAS was the way in which it can be exploited even when it has been correctly installed and functioning the way it was intended. According to the Loss Prevention Investigator:

Some of the practices of professional thieves and even people that associate with certain people within a community know how to beat EAS systems. The EAS tagging that we have can be 'beaten', three or four main ways and good crooks or people that associate with people that target our stores would know those ways of doing it.

This highlights the fact that an EAS system can be exploited by people who know about the technology. It was also understood by the Night-fill Captain that: "people are aware that EAS is out there, people know about it, so they can work around it." Poor work practices at store level also contribute to the ineffectiveness of EAS. "Store practices have an effect. Double tagging, bending tags past 90 degrees, putting tags behind metal, those sorts of things all detract from the system," explained the Loss Prevention Investigator. EAS tags are generally damaged because they are applied manually by hand, hence it is important to realize that retail employees play an active role in overall workings of an EAS system. 
The Store Trading Manager highlighted the fact that the EAS system requires staff members to work as part of the system. Apart from manually attaching tags to products, staff members must react to the EAS alarm system and act accordingly. She said "I don't think the culture's there for it..." Occasionally staff members at point of sale do not respond to the alarm system appropriately. Employees either fail to respond to an alarm, or when a customer activates the alarm the employee assumes that they did not deactivate a tag and allow the customer to leave the store. In this typical scenario, the employee has not taken into account the possibility that the customer may in fact have a packet of batteries in their bag. The Store Trading Manager claimed that the EAS gates are not monitored properly and responding to the system's alarm is not always enforced by staff supervisors.

Retail employees agreed that EAS plays an important role in their loss prevention strategy. According to the Grocery Manager "at the moment, it's the best it can be." If the EAS system is operating at an optimum level and in the way in which it was designed, it raises much concern when reflecting back on some of the short comings of the system. The retailer's EAS system may play an active role in minimizing product shrinkage at point of sale, but what about across the entire retail supply chain?

\section{Product shrinkage}

To ensure stock levels are maintained in-store, an efficient supply chain is required to provide an uninterrupted supply of products for shelf replenishment. However, it is far from unusual to come across an empty shelf in a supermarket. On many occasions, this empty shelf can be directly linked to theft or unsupplied stock due to warehouse discrepancies, both of which contribute to product shrinkage - the retailer's dilemma. When Loss Prevention Manager (2) was asked whether product shrinkage was a major concern to his organization he replied: "[i]t's a huge problem, especially from distribution centre to retail outlet." This concern reinforces the importance of this issue to the retailer and is fundamental to this study. But from a retailer's perspective, what actually constitutes product shrinkage?

\subsection{Factors contributing to shrinkage}

From the retailer's perspective, product shrinkage is broken into two main categories: known and unknown. "Loss Prevention Investigator: At the end of each half of the financial year we record an unknown shrinkage which is obviously the difference between our bookstock and our physical counts at stock take times. So there are two separate figures. I Interviewer: So there is known and unknown? I Loss Prevention Investigator: Yes." The contributing factors of known shrinkage are calculated progressively throughout the financial year by the retailer. For example, the retailer may calculate that $75 \%$ of stock was lost due to warehouse discrepancies, $20 \%$ due to internal theft and $5 \%$ due to other sources. Whereas, the figure found for unknown shrinkage is calculated only twice a year by stock take and can be contributed to by any number of sources. It is significant that unknown sources were the largest contributor to product shrinkage (Store Manager; Store Services Manager).

According to the retailer's Grocery Manager of a supermarket in Sydney's south, product shrinkage is "damaged stock, theft, warehouse discrepancies, paper work errors; not checking stock correctly off invoices, recalled stock and withdrawn stock." In the retail industry, poor stock control across the supply chain covers misrouted and unsupplied products due the common occurrence known as a warehouse discrepancy. More specifically, it was discovered that warehouse discrepancies were the largest contributor to product shrinkage. "Through experience I would say warehouse discrepancies, that's the biggest one," explained the Store Trading Manager. A warehouse discrepancy was described as the difference in what the retailer is charged for, and what they actually receive from the warehouse or supplier (Loss Prevention Manager (1); Store Trading Manager). The Grocery Manager further supported this by stating: " $[\mathrm{t}]$ he main contributor is warehouse discrepancies and number two would be theft." In this instance, it was discovered that the two main contributors to product shrinkage were warehouse discrepancies and internal and external theft. Warehouse discrepancies are largely a procedural based problem, as thoroughly explained by the Loss Prevention Manager (1):

Look there's a couple of thoughts on it. There has been some research done in the States, they tend to do most of the loss prevention type research. They tend to think that internal theft is probably the bigger contributor. I don't know if that would be the case, certainly external theft in [region] that I look after, the main core chunk of Sydney from eastern suburbs out to the western suburbs certainly external theft I think plays a bigger part than the actual internal theft. So you've got your internal paperwork errors and procedural errors which result in loss. You've got internal theft and certainly external theft and they're probably the three drivers for shrinkage. But certainly I can say within [region] external theft would probably play the predominant role. But if you look at it on a 
national basis procedures would probably tend to take over.

From this extract it was therefore discovered that the three main contributors to product shrinkage could be recognized in order of the severity in which they contribute as: (i) warehouse discrepancies (errors due to procedures); (ii) external theft; and (iii) internal theft. In a recent study conducted by the National Retail Security Survey, it was discovered that internal theft caused 46 percent and shoplifting caused 32 percent. This study takes an opposing stance compared to that of the Loss Prevention Manager (1) although external theft encompasses more than shoplifting alone. Figure 3 illustrates the breakdown of known and unknown sources to product shrinkage.

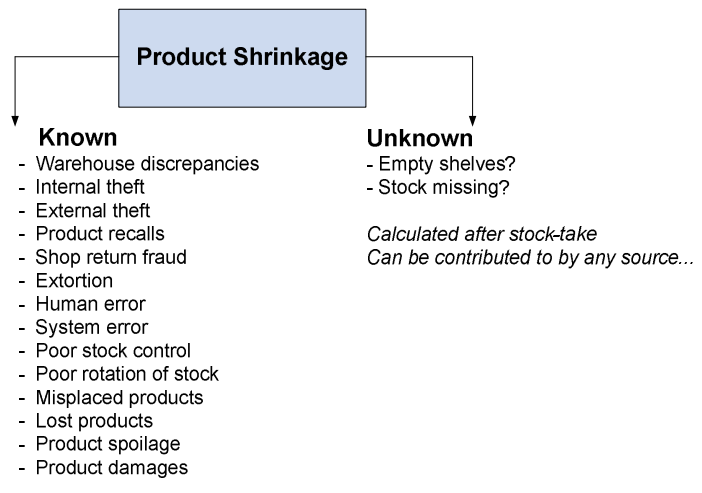

Figure 3. Contributing factors to product shrinkage

\subsection{What products commonly constitute shrinkage?}

Both high-end products and a variety of other products were found to contribute to product shrinkage. These included: batteries, razor blades, liquor and products from the health and beauty range. Table 1 summarizes the main types of products (including brand names) that were identified by all interviewees as items that constitute product shrinkage.

To support theories upheld by the retailer, similar results were found by the Food Marketing Institute in 2003. It was also discovered that items with a high resale value and items that are easily concealed could go missing at any point across the retail supply chain. The Night-fill Captain of one of the Sydney-based stores said: "[b]asically, it's anything they can get their hands on. If the consumer wants something they'll take it. The size is a variable; it doesn't really matter if they can sneak out of the store they'll get it out. People are pushing trolleys of stock, mountains stock out through liquor, with observant staff catching them, so size isn't really a factor." However, what are the primary factors that have a direct influence on the possibility of a product being transported to the wrong store or the unknown disappearance of a particular product?

Table 1. Products and associated brands often named as contributing to product shrinkage by the retailer

\begin{tabular}{|l|l|}
\hline Product Category & Product Ty pes \\
\hline Electrical & Batteries, DVDs, CD-RWs, multimedia, electrical goods \\
\hline Health \& Beauty & Cosmetics (Olay), skin care (Dove), deodorant, vitamins \\
\hline Oral Care & Toothpaste (Sensodyne) \\
\hline Personal Care & Razor blades (Gilette.Mach3̈), other toiletries \\
\hline Hair Care & Shampoo \& conditioner (Pantene, L'Oreal, Garrier) \\
\hline Liquor & Spirits and wines (Jim Beam, Johnny Walker) \\
\hline Pet Supplies & Pet medicated tablets (ExelPet) \\
\hline Medical & Analgesics (Panadol), other medic al products \\
\hline Grocery & Meat (fresh), olivę oil, baby formula \\
\hline Other & Cigarettes \\
\hline
\end{tabular}

\section{Product shrinkage in the supply chain- a process, technology or people problem?}

Contributing sources to product shrinkage are considered to originate from a process, technology or people problem. These three factors collectively create the foundation for product shrinkage and its regular occurrence in the retail industry. When the Loss Prevention Manager (1) was asked whether product shrinkage was a process problem, technology problem or people problem, he responded: "[a]ll three would contribute to it in some way." The following retail based examples in Table 2 are to provide a context in which the three can be understood.

Table 2. Retail-based Examples of Process, Technology and People Problems in the Supply Chain

\begin{tabular}{l}
\hline Process \\
- manual stock takes to calculate unknown shrinkage \\
- the way in which products are picked and shipped at the \\
distribution centre \\
- manual procedures for accepting deliveries at a back-dock \\
\hline Technology \\
- erroneous scans and other problems with the barcode system \\
- thieves with knowledge and ability to defeat the EAS system \\
- unreliable anti-theft EAS system \\
People \\
- checkout operators not responding to the EAS alarm system \\
- the existence of dishonest employees and thieves \\
- applying EAS tags incorrectly i.e. double tagging, bending tags \\
beyond 90 degrees
\end{tabular}

When the Loss Prevention Investigator was asked about his opinion on these three factors affecting product shrinkage, he replied: I think it encompasses all of it. We certainly have some processes that need to be looked at. The way that our DC [distribution center] is structured, the way that they ship items from there certainly needs to be looked at and will be over a period of time. Obviously, to take out the human side of 
it would certainly help because unfortunately humans make mistakes and that does certainly cause some errors. The other side of it is theft which is very much a human side of it, people walking in and just stealing from us. And also poor practices in-stores also contribute where we don't follow our processes and procedures. It was revealed in this case that both processes and people were a primary influence to the many sources of product shrinkage. The retailer was concerned about the processes involved at the distribution centre when organizing the transportation of goods across the retail supply chain. In addition, human error, poor practices in-store and theft were recognized as being contributors to the problem of product shrinkage.

The Store Services Manager also identified the issue of poor procedures when receiving goods at the backdock as a process problem. "[T]here is no way that you can physically scan every item that comes in on the load. There's no way." Employees involved in the study were asked when their superiors begin to ask questions about loss. As emphasized by the Store Trading Manager, based on previous audits a product shrinkage figure is predicted for each individual store: "[s]o if it's over that, then they will definitely come in and investigate and usually the first thing they look at is systems and procedures in the store. If they're not right then it's automatically the store's responsibility to get it right." It was certainly recognized that procedures, closely connected to processes are critical in minimizing product shrinkage levels. These three factors may influence product shrinkage levels, but whereabouts does it occur across the retail supply chain?

\section{Where does product shrinkage occur?}

Stores within each of the retailer's regions receive goods from both company owned warehouses and third party suppliers. Company owned warehouses consist of one regional distribution center (RDC) and five local distribution centers (DC). An RDC may supply products to hundreds of retail outlets, whereas a DC will only deliver goods to a designated region. The majority of stock is supplied from company owned distribution centers, yet interestingly there are more third party suppliers. Third party suppliers are external to the retailer and are known as direct suppliers. The retailer engages in hundreds of transactions with suppliers daily. All stock is ordered using an automatic stock ordering system. It was estimated by the Store Manager that approximately 200 transactions are made daily between his store and its suppliers. The Loss Prevention Manager (1) stated that a "continuous electronic barrage of orders" is required to keep retail outlets fully stocked in order to satisfy customer demands. Coordinating these orders across the entire retail supply chain and scheduling deliveries is an enormous task performed by the retailer using its warehouse and logistics services. During this process, product shrinkage occurs at various points, whether it be at the distribution centre, in-transit, or when a delivery is received by a back-dock attendant at a retail outlet. When the Loss Prevention Manager (1) was asked where most product shrinkage occurs across the retail supply chain he replied:

Look we are aware that you can have theft issues with truck drivers. Truck seals aren't put on, we know stock can go missing. We have had instances where drivers have been caught. I suppose our processes are not conducive to checking, so you're relying on what the DC says that they send you, is in fact what you are receiving. So if you have a store that has 10 palettes of stock delivered from a DC, unless we pick-up at store level the fact that we're missing something and it's pretty hard if you've got 10 palettes of stock, night-fill come in and fill it. Unless you do a line-by-line check, how do you know what's missing? And certainly the stores put in an order for X-amount we're trusting that that store will get X-amount, if they don't, a lot of that tends to go uncaptured. If you look at the case of say [Cold-Storage Logistics Company] which is one of our external suppliers, they warehouse it and distribute our cold stock, but there's massive issues with them. It's not uncommon for a load to come in several thousand dollars short. Do we pickup on that fact? No, we don't. Because it comes in, it goes into a cool room and then night-fill or then your perishable people will come through and fill, it's pretty hard to pickup on the fact that you're short on a line, it might be a couple of days down the track and you might say where's that? You then go through and make your stock adjustments so [automatic stock ordering system] will then reorder it, but by that time it's too late to put in a discrepancy. Big problems with [Cold Storage Logistics Company], the sooner that comes in-house so we get some better control of it the better.

Issues raised here by the Loss Prevention Manager are critical when recognizing the contributing factors of product shrinkage. Contributing factors across the retail supply chain include: (i) internal/external theft by vehicle drivers; (ii) assuming deliveries are correct; (iii) not realizing deliveries are missing stock; (iv) being too late to notify the automatic stock ordering system of a discrepancy; and (v) problems with direct suppliers e.g. the retailer's direct supplier of cold goods. These factors reveal that product shrinkage occurs at various points across the supply chain. The Liquor Manager also believes when an order made by the automatic stock ordering system is picked at the 
warehouse, the incorrect amount or type of product is often dispatched. Inconvenient and time consuming tasks, such as the process of having to return an incorrect order, are then necessary. Incorrect orders may require additional labor intensive tasks to be performed, however, there are more serious consequences that accompany product shrinkage.

\subsection{The consequences of product shrinkage}

There are a number of consequences that are directly related to product shrinkage. The primary consequence of product shrinkage is financial loss. When asked how much stock is lost over a period of 12 months, the Loss Prevention Manager (1) replied: "its millions of dollars in unknown shrinkage." Product shrinkage is a relentless force in the retail industry and the loss it causes is extremely high. When the Loss Prevention Investigator was asked how much stock is lost, he said: "[s]ome stores will lose as little as $\$ 50,000$ in six months, other stores will lose half a million in six months, depending on the size of the store. I suppose if you take an average you're looking at somewhere around $\$ 350,000$ in six months." In the Store Trading Manager's experience, unknown product shrinkage totaled $\$ 360,000$ for a period of six months. Apart from the direct financial loss incurred other forms of loss involve additional costs (e.g. EAS systems, loss prevention staff), additional labor (e.g. security guards, manually applying EAS tags), and out of stocks (e.g. empty shelves effects sales levels and customer satisfaction). According to the Grocery Manager, due to theft alone prices can rise up to 15 percent ultimately affecting customers. If products can be accurately tracked across the supply chain it is anticipated that it will have a direct effect on product shrinkage.

\section{Tracking products across the supply chain}

The retailer currently tracks products across the retail supply chain using a combination of barcodes and manual paper work procedures. When asked how products were tracked from distribution centre to retail outlet, the Store Trading Manager replied: 'there's that big void in the middle where an order goes onto the load list and we can check it line-by-line if we want, but we just don't have the man power. It's not a standard thing that you check a load list line-by-line and given that here they get 30 to 35 pallets a night." As this employee suggests, it is unfeasible to count each individual carton of a large delivery using existing procedures.

The distribution centre coordinates the largest deliveries to be transported to the retail outlet.
Currently, employees rely on the DC to select the desired goods and ship them accordingly. The current system has the ability to track products to a certain extent, but acknowledged by the Grocery Manager "it's not $100 \%$ accurate, probably because they're expecting people at the warehouse to do it correctly." As the DC is responsible for other discrepancies, it can be assumed that other procedures carried out at the same site are also heavily flawed. Deliveries may arrive at a store's back-dock missing a number of products, so how are products monitored during transportation?

The retailer uses Global Positioning Systems (GPS) as a means to track vehicles across the supply chain. Using a pre-planned route, GPS-enabled trucks are tracked from the distribution centre to the retail outlet. The system is designed to provide the geographical position of the truck during the transportation of goods. However, GPS does not provide information regarding the status of goods onboard. A number of voids exist across the retail supply chain where products fail to be accurately tracked. When asked if products were tracked across the supply chain, the Loss Prevention Manager (1) said: “[p]roducts aren't tracked. If you're talking about electronic tracking or things like that, then no." In this response, the Loss Prevention Manager (1) is referring to new RFID systems designed to track products across the supply chain.

\section{The retailer's perceptions of RFID}

Employees of the retailer were asked if they were aware of the latest RFID systems and their benefits. It was found that employees involved in the study had a positive outlook on new RFID technologies yet were unaware of the technologies' commonly reported primary benefits. Loss prevention employees had a far better understanding of the technology than managers from other departments. As explained by the Loss Prevention Manager (1): "I have a basic understanding. There are all sorts of things product tracking, inventory management, there's a whole range of things." Furthermore, he explained:

I haven't done any research in it, there would be a whole range of things. There'd be all sorts of cost benefits there I would assume in inventory management right down to even, we may even be able to know the product size and weights in terms of transport we'd be able to work out to the nearest cubic centimeter how much stock we can fit on a truck. Whether we are being over charged in transport costs, for weight or pallet space or size, they'd probably be a whole range of hidden benefits there that you probably haven't even thought of before.

It was interesting to discover that loss prevention managers focused on secondary benefits of the 
technology. Rather than its ability to provide total visibility of stock across the supply chain and ultimately a means to minimize product shrinkage, employees concentrated on some of the benefits it could bring to point of sale. For example, the Loss Prevention Manager (1) recognized that "you can put $\mathrm{X}$-amount of stock in a trolley with RFID that are all tagged, pass it through some antennas and you know exactly what went out of the store and if it was paid for."

The Store Trading Manager claimed to have little knowledge of RFID as a technology with the ability to track products across the supply chain. However, she declared that it would definitely benefit the retailer as it would "probably reduce our shrinkage by a huge amount, not to mention the time spent actually adjusting the stock on hand because there have been miss-picks and things haven't gone right." In this instance, the Store Trading Manager not only suggests that RFID is likely to minimize product shrinkage, but also the manual procedures. The Store Services Manager also had an appreciation for the technologies' ability to minimize manual procedures at store level. She claimed that less labor would be required when manually stamping products with the store stamp as a new RFID system would require suppliers to do it at the product's point of manufacture. She also believed that if the retailer was to implement an RFID system that its imperative that suppliers also be part of the overall system as "[i]t would be of no benefit otherwise." The Store Services Manager believed that if such a system was introduced, their suppliers would most likely comply: "[t]he suppliers usually do come into line with any new systems that we are bringing in so I couldn't see that there would be a problem." She also highlighted the fact that RFID tagging would most probably have an effect on the total price of a product, but she believed that this increase could be counteracted if product shrinkage was kept to a minimum.

An organization willing to adopt a new RFID system must be able to see potential for a return on investment (ROI). When the Loss Prevention Manager (1) was asked whether he thought the retailer would ever be interested in investing in an RFID solution he responded: "[t]here's always that cost versus benefit exercise and if the sums are right, then yes." As identified by Global Standards One, in the case study called the Australian Demonstrator Project (which claimed to be Australia's first case study), it was revealed that it is "necessary to estimate the potential benefit that will come from deploying RFID and improving the business process using the data that the system provides" [2]. It is in this light, that testing an RFID system is highly recommended prior to total rollout as it assists in building an expected ROI.

\section{Conclusion}

It was discovered that the retail organization currently utilizes two technologies as part of a loss prevention strategy; a barcode auto-ID system and an EAS anti-theft system. Operating independently, it was revealed that both technologies possess a number of limitations which consequently present adverse challenges to the retailer. The barcode system can record damaged products and detect targeted products or areas, yet the technology plays a minor role as part of the retailer's loss prevention strategy. Even though the retailer was currently testing a new EAS system throughout five liquor stores, the technology was still considered a deterrent rather than a total solution. It was also discovered that professional thieves avoid triggering the alarm using a variety of methods and staff members regularly neglect standard procedures readily relied on by the EAS system. These inadequacies expose a weakness in the retailer's loss prevention strategy as a result effecting product shrinkage levels. Made up by contributing sources, the two main categories of product shrinkage identified were known and unknown, with unknown representing a larger value of the two. Contributing factors to product shrinkage were found to come from a diverse range of sources and through various activities. Warehouse discrepancies and theft were identified as the two highest sources of product shrinkage. Whether it involved a standard company procedure or an illegal activity, it was found that during most of these events provisions were lacking to effectively counteract these activities. It was verified, particularly by loss prevention staff members that all sources originated from the combination of three factors; process, technology and people. Furthermore, the loss prevention department claimed that product shrinkage across the supply chain was one of the department's main challenges, especially when transferring goods from distribution centers to retail outlets. This dilemma necessitates an alternative solution be found to minimize product shrinkage across the retail supply chain.

\section{References}

[1] Lahiri, S., (2006) RFID Sourcebook, IBM Press, Pearson Education, Upper Saddle River, p. 77. 
[2] Global Standards One (GS1) Australia (2006) EPC Network Australian Demonstrator Project Report, http://www.gs1au.org/assets/documents/info/case_ studies/case_epc_demo.pdf [18 September 2006] 